\title{
THE SOLUTION OF TWO-DIMENSIONAL HEAT CONDUCTION PROBLEMS FOR PREDICTING OPERATING TEMPERATURE AND POWER HANDLING CAPABILITIES OF HYBRID CIRCUITS
}

\author{
G. P. FERRARIS and M. TUDANCA \\ G.T.E. Telecomunicazioni, S.T. Av., 20060-Cassina De'Pecchi, Milan, Italy
}

(Received July 10, 1979)

\begin{abstract}
The problems of heat conduction in hybrid thin and thick film circuits have been investigated using both analytical and numerical approaches.

The calculations were restricted to two dimensions by assuming zero temperature gradient across the thickness of the substrate (slightly more than half millimeter).

All normally recognized parameters were taken in to consideration, such as film temperature, power dissipated, substrate area, etc.

Allowances have also been made for lead conduction and connection technology, for horizontal or vertical circuit assembly, and for flush or stand-off mounting on the mechanical support.

The measured results for practical cases show close agreement with the theoretical calculations.

This approach provides a simple tool for the calculation, at an early design stage of power handling capacities of hybrid circuits using composite resistive configurations.

Very little difference was found between temperatures predicted from the theoretical approach and those measured in practical cases of circuits under load.

The availability of such accurate design information means that the stability, life, and reliability of hybrid circuits can be predicted with considerable accuracy at an early design stage.
\end{abstract}

\section{INTRODUCTION}

To investigate analytically heat conduction problems in hybrid circuits, models were restricted to two dimensions assuming that the thickness of the substrates was negligible for the usual applications in relation to the dimensions of the plane of the substrate; also because the material employed (alumina ceramic) had a relatively high thermal conductivity. We also assumed that coefficients of convection were identical for front and back surfaces of the substrates and that radiation effects linearized for the temperature intervals used were included in the convection coefficient itself. Finally, we assumed that the temperature of the powered resistive films was uniform over the whole area at the hottest film temperature.

Key words $-t=$ thickness of substrates in mm;

$a$ = radius of substrates in $\mathrm{mm}$;

$r_{0}=$ radius of resistive film in $\mathrm{mm}$;

$K=$ thermal conductivity of substrate in $\mathrm{mW} \mathrm{mm} / \mathrm{mm}^{2}{ }^{\circ} \mathrm{C}$;

$h=$ coefficient of convection in $\mathrm{mW} / \mathrm{mm}^{2}{ }^{\circ} \mathrm{C}$;
$T_{f}=$ overtemperature of resistive film in ${ }^{\circ} \mathrm{C}$;

$P_{w}=$ power density of resistive film $\mathrm{mW} / \mathrm{mm}^{2}$;

$D=A_{s} / A_{f}=$ ratio between substrate area and film area;

$R_{L}=$ thermal resistance of leads in ${ }^{\circ} \mathrm{C} / \mathrm{mW}$;

$T=$ excess temperature over ambient on substrate zones not covered by resistive films in ${ }^{\circ} \mathrm{C}$.

2. CIRCULAR SHAPED SUBSTRATES WITH CENTERED CIRCULAR RESISTIVE FILMS

\subsection{Theory}

For a ring of thickness $t$ included between radii $r$ and $r+\Delta r$ (Figure 1) $r>r_{0}$ the heat flux is:

$$
\begin{aligned}
-K 2 \pi r t\left[\frac{d T(r)}{d r}\right]_{r}= & -K 2 \pi(r+\Delta r) t\left[\frac{d T(r)}{d r}\right]_{r+\Delta r} \\
& +h \pi\left[(r+\Delta r)^{2}-r^{2}\right] 2 T(r)
\end{aligned}
$$




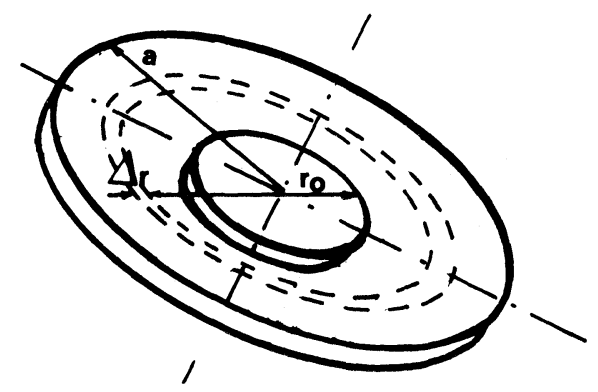

FIGURE 1 Circular substrate

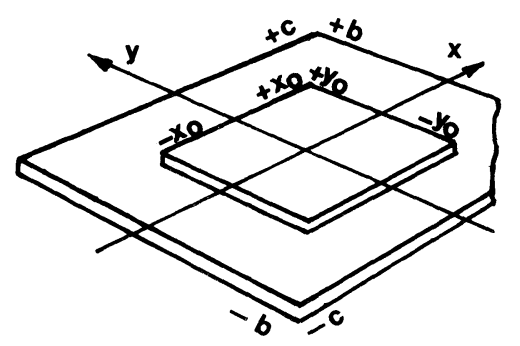

FIGURE 2 Rectangular substrate

$$
\begin{aligned}
{\left[\frac{d T(r)}{d r}\right]_{r+\Delta r} } & =\left[\frac{d T(r)}{d r}\right]_{r} \\
& +\frac{d^{2} T(r)}{d r^{2}} \Delta r\left(\text { Average theorem }{ }^{1}\right)
\end{aligned}
$$

From Eqs. (1) and (2), disregarding the second order terms $(\Delta r)^{2}$ :

$$
\frac{d^{2} T}{d r}+\frac{1}{r} \frac{d T}{d r}-\frac{2 h}{K t} T=0
$$

substituting $W^{2}=\frac{2 h}{K t}$ and $W r=Z$

$$
\frac{d^{2} T}{d Z^{2}}+\frac{1}{Z} \frac{d T}{d Z}-T=0
$$

The solutions of Eq. (4) are, with $J_{0}, Y_{0}$, first and second type Bessel functions, ${ }^{2}$ :

$$
T(r)=A J_{0}(i w r)+B Y_{0}(i w r)
$$

To fix constants $A$ and $B$ the following conditions were imposed:

$$
T\left(r_{0}\right)=T_{f}(\text { film overtemperature })
$$

$-K 2 \pi a\left[\frac{d T}{d r}\right]_{\substack{r=a \\ t=0}} 0$ disregarding the heat losses from the edge of the substrate

$$
T(r)=T_{f} \frac{Y_{1}(i w a) J_{0}(i w r)-J_{1}(i w a) Y_{0}(i w r)}{J_{0}\left(i w r_{0}\right) Y_{1}(i w a)-Y_{0}\left(i w r_{0}\right) J_{1}(i w a)}
$$

The power dissipated from substrate zones not covered by film is:

$$
\begin{aligned}
P s=2 \int_{r_{0}}^{a} h 2 \pi r T(r) d r=\frac{4 \pi h}{w i} T_{f} r_{0} \\
\\
\frac{\left\{Y_{1}\left(i w r_{0}\right) J_{1}(i w a)-J_{1}\left(i w r_{0}\right) Y_{1}(i w a)\right\}}{\left\{J_{0}\left(i w r_{0}\right) Y_{1}(i w a)-Y_{0}\left(i w r_{0}\right) J_{1}(i w a)\right\}}
\end{aligned}
$$

The power dissipated from the resistive film is:

$$
\begin{aligned}
P_{f}=T_{f} A_{f}\left(h+h_{f}\right) \quad h_{f} & =\text { convection coefficient of } \\
& \text { film } \\
h & =\begin{array}{l}
\text { convection coefficient of } \\
\text { substrate }
\end{array}
\end{aligned}
$$

If $N_{L}$ leads, each with thermal resistance $R_{L}$ are mounted on the substrate periphery where the overtemperature is $T(a)$, power dissipated from the leads is:

$$
\begin{aligned}
& P_{L}=\frac{T(a) N_{L}}{R_{L}}= \\
& \frac{N_{L}}{R_{L}} T_{f} \frac{\left\{Y_{1}(i w a) J_{0}(i w a)-J_{1}(i w a) Y_{0}(i w a)\right\}}{\left\{J_{0}\left(i w r_{0}\right) Y_{1}(i w a)-Y_{0}\left(i w r_{0}\right) J_{1}(i a)\right\}}
\end{aligned}
$$

Total power dissipated is:

$P=P_{f}+P_{s}+P_{L}=P_{d}=$ power across resistive film

$$
P_{w}=\frac{P_{d}}{A_{f}}=\frac{P_{f}}{A_{f}}+\frac{P_{s}}{A_{f}}+\frac{P_{L}}{A_{f}}=\text { power density }
$$

From Eqs. (7), (8), (9), and (11):

$$
\begin{aligned}
\frac{P_{w}}{T_{f}}= & h_{f}+h+2 h \sqrt{\frac{2 \pi K t D}{h A_{s}}} F\left(a, w, r_{0}\right) \\
& +\frac{D N_{L}}{A_{s} R_{L}} F^{\prime}\left(a, w, r_{0}\right) D=A_{s} / A_{f}
\end{aligned}
$$

$F=\frac{\left\{-i J_{1}(i w a)\right\}\left\{-H_{1}^{(1)}\left(i w r_{0}\right)\right\}-\left\{-i J_{1}\left(i w r_{0}\right)\right\}\left\{-H_{1}^{(1)}(i w a)\right.}{\left\{J_{0}\left(i w r_{0}\right)\right\}\left\{-H_{1}^{(1)}(i w a)\right\}+\left\{-i J_{1}(i w a)\right\}\left\{i H_{0}^{(1)}\left(i w r_{0}\right)\right\}}$

$F^{\prime}=\frac{\left.\left\{J_{0}(i w a)\right\}-H_{1}^{(1)}(i w a)\right\}+\left\{-i J_{1}(i w a)\right\}\left\{i H_{0}^{(1)}(i w a)\right\}}{\left\{J_{0}\left(i w r_{0}\right)\right\}\left\{-H_{1}^{(1)}(i w a)\right\}+\left\{-i J_{1}(i w a)\right\}\left\{i H_{0}^{(1)}\left(i w r_{0}\right)\right\}}$ 
$H_{p}^{(1)}(x)$ being the Hankel functions derived from the equation

$$
Y_{p}(x)=i J_{p}(x)-i H_{p}^{(1)}(x)
$$

All functions included in $F$ and $F^{\prime}$ have real values for imaginary variables and are tabulated. ${ }^{2}$

\subsection{Experiments with Circular Substrates}

Circular alumina substrates of thickness $0.635 \mathrm{~mm}$. (25 mils) with central circular resistive Tantalum nitride films were produced. ${ }^{3}$ The film temperatures were measured with an infrared pyrometer at the hottest point. Care was taken to suspend the substrates vertically and power them with long thin copper wires to minimise lead losses. Eq. (12) was first tested for validity without leads on the assumption that, for constant $D$, the ratio $P_{w} / T_{f}$ is independent of the power across the resistor.

Power densities were chosen so that temperatures fell in the range 90 to $200{ }^{\circ} \mathrm{C}$ where the theoretical assumption of radiation effects can reasonably be considered valid, and the infrared pyrometer had the most expanded scale. Obviously, temperatures above $200^{\circ} \mathrm{C}$ are in excess of those normally applicable to hybrid microcircuits. From the data in Table I we o bserve that the values of $P_{w} / T_{f}$ show a tendency to diminish with increasing power but these effects, probably due to radiation emission, can reasonably be disregarded in the temperature range considered, because they introduce an error of less than $\pm 5 \%$ in predictions of temperature and this is the limit of the validity of our theory. The results of Table I, column (a), were plotted against $D$ on a $\log \log$ scale (Figure 3). Assuming the value from the data sheets for $\mathrm{AL} 772$ as the thermal conductivity of the substrate, $\left(K=36 \mathrm{~mW} \mathrm{~mm} / \mathrm{mm}^{2}{ }^{\circ} \mathrm{C}\right)$ experimental values for the convection coefficient of the substrate (h) were calculated by extrapolation since from Eq. (12):

$$
\begin{aligned}
& \frac{P_{w}}{T_{f}}=h_{f}+h+2 h \frac{\sqrt{2 \pi K t D}}{\sqrt{h A_{s}}} F \simeq \\
& 2 h\left\{1+\frac{\sqrt{2 \pi K t D}}{\sqrt{h A_{s}}} F\right\} N_{L}=0 D \gg 10
\end{aligned}
$$

$h_{f}$ and $h$ being quantities of the same order, and $\mathrm{Eq}$. (14) is:

$$
\frac{P_{w}}{T_{f}}=2 h \quad \text { for } D=1 \quad N_{L}=0
$$

Experimental values of the convection coefficient $\left(h_{f}\right)$ were successively calculated from values of $P_{w} / T_{f}$ for $D \ll 10$ and Eq. (12) was plotted (Figure 3, curve 1) showing a clear correlation between the theoretical and practical cases.

TABLE I

Experiments with circular substrates

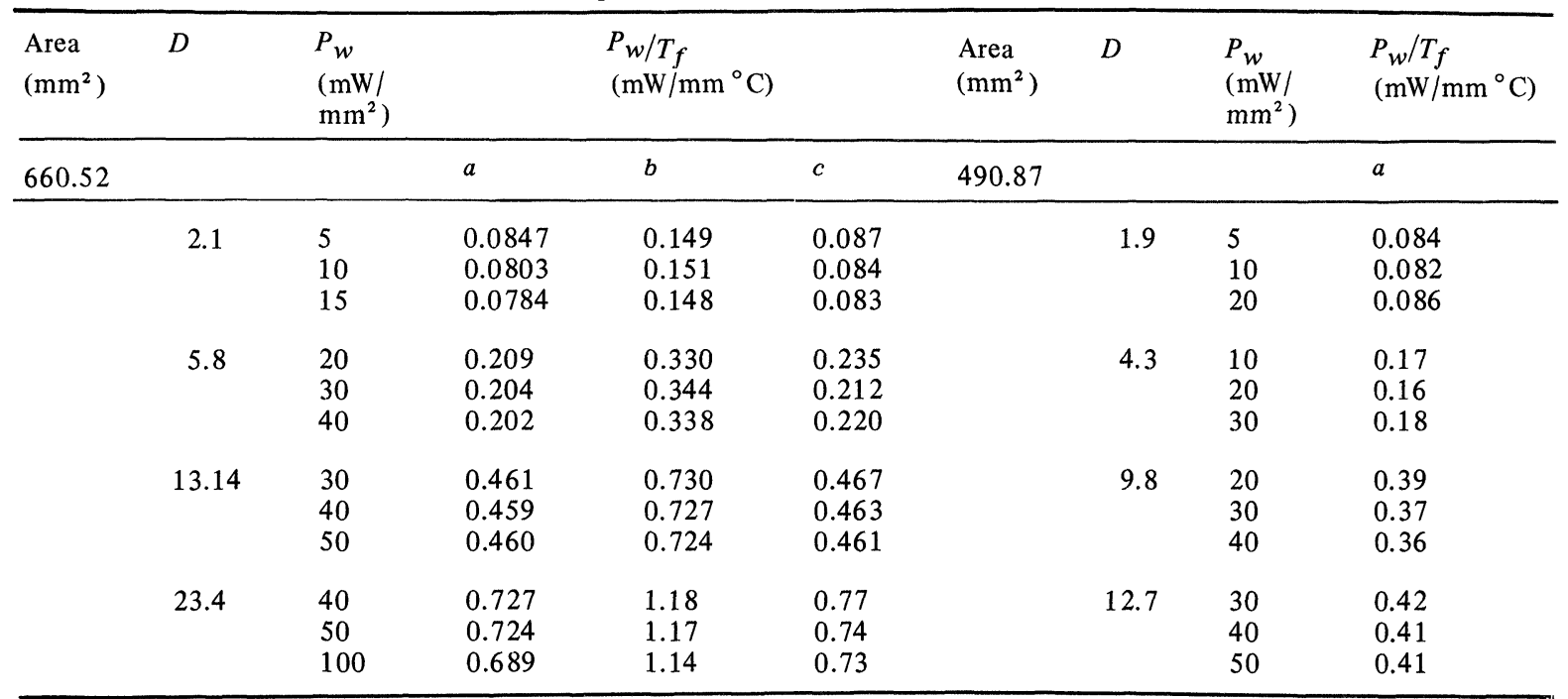

\footnotetext{
$a_{\text {without leads; }}{ }^{b}$ with 6 leads mounted on copper heat sink; ${ }^{c}$ with 6 leads mounted on PCB
} 


\section{RECTANGULAR SHAPED SUBSTRATES WITH CENTRAL RECTANGULAR RESISTIVE FILM}

\subsection{Theory}

Assuming exactly the same conditions as in the circular case (Figure 2) but applied to rectangular geometries:

$$
\begin{aligned}
\frac{\partial^{2} T(x, y)}{\partial x^{2}} & +\frac{\partial^{2} T(x, y)}{\partial y^{2}}-W^{2} T(x, y)=0 \\
-b \leqslant-y<-y_{0}, & y_{0}<y \leqslant b, \\
-c \leqslant-x<-x_{0}, & x_{0}<x \leqslant c
\end{aligned}
$$

Since the geometry is symmetrical, Eq. (16) was solved numerically for the first quadrant. Using a finite increment method:

$$
\begin{aligned}
\frac{\partial T(x, y)}{\partial x}=\frac{\Delta T(x, y)}{\Delta x} & \\
& =\frac{T\left(x+H_{x} / 2, y\right)-T\left(x-H_{x} / 2, y\right)}{H_{x}}
\end{aligned}
$$

$$
\begin{aligned}
\frac{\partial^{2} T(x, y)}{\partial x^{2}} & =\frac{\Delta^{2} T(x, y)}{\Delta x^{2}} \\
= & \frac{T\left(x+H_{x}, y\right)+T\left(x-H_{x}, y\right)-2 T(x, y)}{H_{x}{ }^{2}}
\end{aligned}
$$

and analogously for the $y$ derivative, transforming Eq. (16) into:

$$
\begin{aligned}
& \frac{\left\{T\left\{(n+1) H_{x}, m H_{y}\right\}+T\left\{(n-1) H_{x}, m H_{y}\right\}\right\}}{H_{x}{ }^{2}} \\
& +\frac{\left\{T\left\{n H_{x},(m+1) H_{y}\right\}+T\left\{n H_{x},(m-1) H_{y}\right\}\right\}}{H_{y}{ }^{2}} \\
& +(-1)\left\{\frac{2}{H_{x}{ }^{2}}+\frac{2}{H_{y}{ }^{2}}+W^{2}\right\} T\left(n H_{x}, m H_{y}\right)=0 \\
& x=n H_{x}, \quad y=m H_{y} \quad n, m \text { integers }
\end{aligned}
$$

The substrate area was quantized as a finite number $N^{2}$ of nodes and meshes each of area $H_{x} H_{y}$; $H_{x}=c / N ; H_{y}=b / N$.

Fixing the conditions of the problem exactly as in

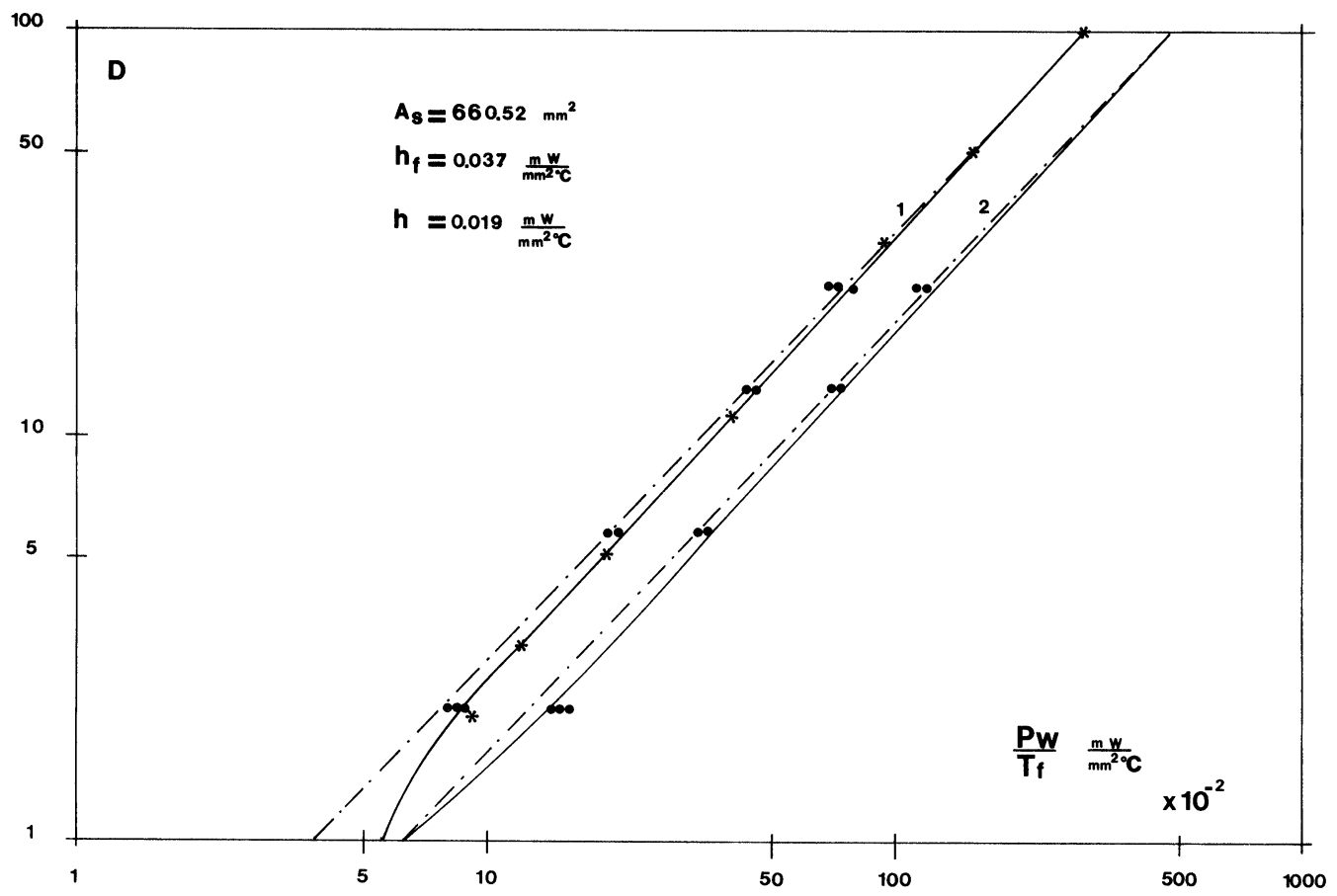

FIGURE 3 Experiments with circular substrate. 
the circular case:

$$
\begin{aligned}
& T\left(n H_{x}, N_{y} H_{y}\right)=T_{f} \quad n=0,1, \ldots N_{x} \\
& N_{y}=y_{0} / H_{y} \\
& T\left(N_{x} H_{x}, m H_{y}\right)=T_{f} \quad m=0,1, \ldots N_{y} \\
& N_{x}=x_{0} / H_{x} \\
& T\left(n H_{x}, H_{y}\right)=T\left(n H_{x}-H_{y}\right) \\
& T\left(H_{x}, m H_{y}\right)=T\left(-H_{x}, m H_{y}\right)
\end{aligned}
$$

In particular, the last two conditions transform Eq. (18) into:

$$
\left\{\frac{\Delta^{2} T(x, y)}{\Delta x^{2}}\right\}_{x=c}=\frac{T\left\{(N-1) H_{x}, m H_{y}\right\}-T\left\{N H_{x}, m H_{y}\right\}}{H_{x}{ }^{2}}
$$

(and analogous for $y$ coordinate)

Writing Eq. (19) for all the $N^{2}-N_{x} N_{y}$ nodes, gives a system of equations easily solved by matrix theory on a computer and the ratio $T_{i} / T_{f}$ of the overtemperature of the node $i$ to the film overtemperature was calculated numerically. Numerical integration over the substrate meshes gives:

$$
\begin{gathered}
\frac{P_{w}}{T_{f}}=\left(h_{f}+h\right)+\frac{8 h A_{m}}{4 A_{f}} \stackrel{N^{2}-N_{x} N_{y}}{\sum_{i}} \frac{T_{i}}{T_{f}} \\
A_{m}=H_{x} H_{y}, A_{f}=N_{x} H_{x} N_{y} H_{y} \\
\frac{P_{w}}{T_{f}}=(20) \\
D=\frac{A_{s}}{A_{f}}=\frac{N^{2}-N_{x} N_{y}}{N_{x} N_{y} H_{x} H_{y}}=\frac{N^{2}}{N_{x} N_{y}}
\end{gathered}
$$

To compare Eq. (21) with Eq. (12) without leads, the following relation between the rectangular and circular cases was imposed:

$$
\begin{aligned}
& (2 c 2 b) / \pi=a^{2}\left(2 x_{0} 2 y_{0}\right) / \pi=r_{0}^{2} \\
& T_{m}=T_{f} \frac{\sqrt{2 \pi K t D}}{\sqrt{h A_{s}}} \frac{F\left(a, r_{0}, W\right)}{(D-1)}
\end{aligned}
$$

It must still be shown that Eq. (21) and Eq. (12) are comparable at the limits of theoretical validity $( \pm 5 \%)$.

\subsection{Experiments with Rectangular Substrate}

Alumina substrates of thickness $0.635 \mathrm{~mm}$. with central rectangular resistive Tantalum nitride films were produced at $1^{\prime \prime} \times 1^{\prime \prime}, 1^{\prime \prime} \times 2^{\prime \prime}, 2^{\prime \prime} \times 2^{\prime \prime}{ }^{3}$ The film temperature was measured at the hottest resistive film point by an infrared pyrometer in identical conditions to those imposed for the circular substrates.

The $P_{w} / T_{f}$ data plotted against $D$, on a $\log \log$ scale, is shown in Figure 4. Also for rectangular substrates the values of $P_{w} / T_{f}$ are independent of the power across the resistive films at the theoretical limits ( $\pm 5 \%)$. Calculation at $D \gg 10$ and extrapolation at $D=1$ gives the experimental values for the convection coefficient. These were substituted in Eq. (12) (continuous curves 1,2 and 3 in Figure 4) and in Eq. (21) (asterisks). The correlation of the points and curves allowed Eq. (12) and statements of Eq. (22) to be used for all further calculations.

\subsection{Experiments with Substrates Mounted Horizontally}

Temperature measurements were repeated with substrates mounted horizontally and values of the parameter $h$ were calculated. Plotting $h$ for vertically and horizontally mounted substrates on a log log scale against $1 / A_{s}$ (Figure 5) gives the following empirical law:

$$
\begin{array}{rlr}
h & =h_{c}(1 / A s)^{0.416} \mathrm{~mW} / \mathrm{mm}^{2}{ }^{\circ} \mathrm{C} \\
h_{c} & =0.26 & \text { for substrate vertically mounted. } \\
h_{c}^{\prime} & =0.22 \quad \text { for substrate horizontally mounted. }
\end{array}
$$

The value $P_{w} / T_{f}=2 h$ is an index of the power handled by substrate, so that, for a maximum overtemperature of $80^{\circ} \mathrm{C}$ on $1^{\prime \prime} \times 1^{\prime \prime}$ substrates, the maximum power that can be dissipated is $\simeq 2 \mathrm{~W} / \mathrm{in}^{2}$. This is the well known value that is widely used as a rule of thumb in hybrid projects and is valid for vertically mounted substrates without leads. This maximum power across $1^{\prime \prime} \times 1^{\prime \prime}$ substrates insures that the temperature of the resistive film is at a maximum of $150^{\circ} \mathrm{C}$ for an ambient temperature of $70^{\circ} \mathrm{C}$ (IEC 115-1). Identical considerations show that, for $2^{\prime \prime} \times 2^{\prime \prime}$ substrates, the maximum power is not $8 \mathrm{~W}$ but only $\approx 4 \mathrm{~W}$ since the $h$ values are different. This can be used in design as a rule of thumb to calculate the minimum area of substrate required for dissipating the maximum anticipated power in a hybrid circuit. 


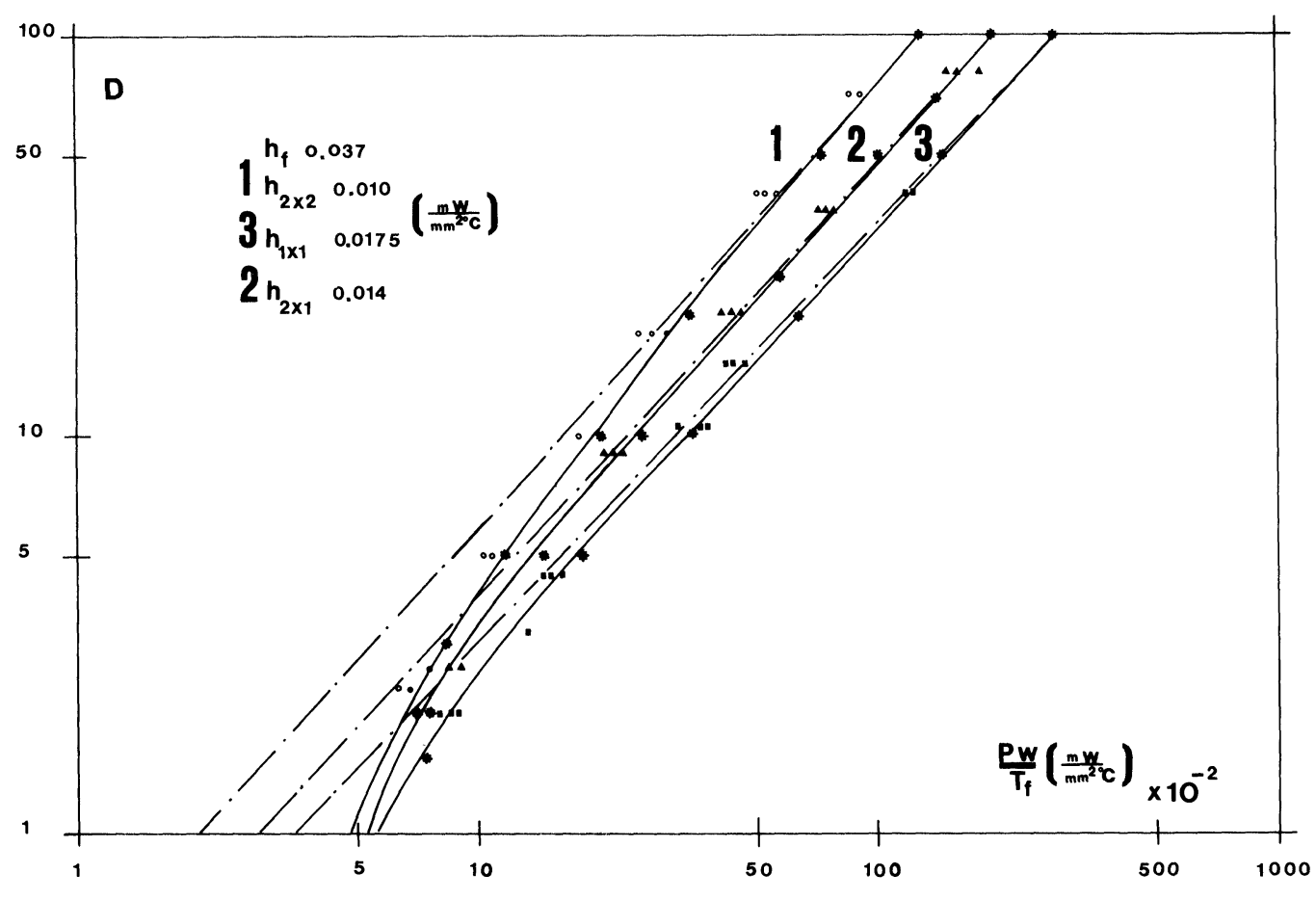

FIGURE 4 Experiments with rectangular substrates.

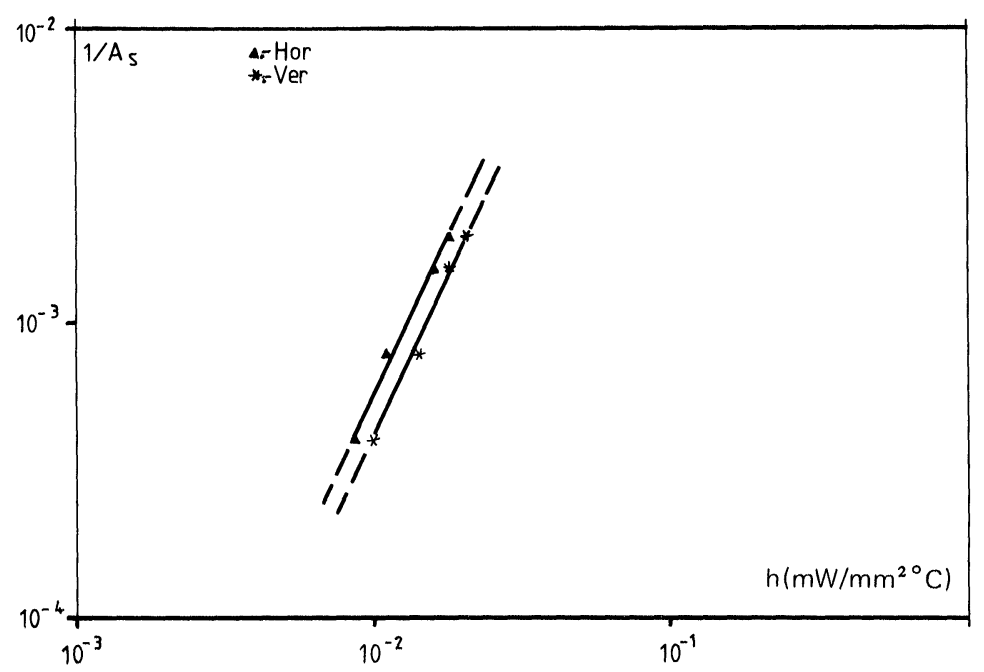

FIGURE 5 Empirical law for convection coefficients of substrates.

\subsection{Experiments with Leads}

To evaluate lead effects, 6 standard GTE leads were soldered on to the periphery of the circular substrates of area $660.52 \mathrm{~mm}^{2}$. The substrates were soldered to a copper heat sink as in Figure 6 to simulate a real situation. The copper heat sink was used to ensure that the ends of the leads were effectively at the ambient temperature so that Eq. (12) could be used. Experimental measurements for vertical position are recorded in Table I, column $b$ and the calculated values of Eq. (12) for the value obtained for $R_{L}=$ 


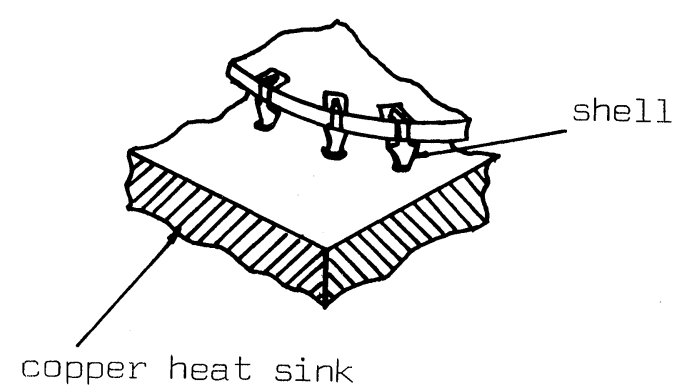

FIGURE 6 Experiments with leads, circular substrate on copper heat sink.

$0.337^{\circ} \mathrm{C} / \mathrm{mW}$ are plotted on continuous curve 2 in Figure 3. Analogous experiments were performed with the substrates mounted on PCBs. The data were recorded in Table I, column $c$. The values obtained are close to those of experiment without leads and within the measurement tolerance. This is due to the poor thermal conductivity of the PCBs which cannot insure ambient temperature at the ends of the leads. To obtain an equivalent thermal resistance for leads on PCBs, experiments were repeated with 22 leads mounted on the substrate periphery and, from calculations, $R_{L}=5.40^{\circ} \mathrm{C} / \mathrm{mW}$.

\section{MEASUREMENTS WITH HYBRID CIRCUITS}

The validity of the theory and of Eq. (12) was verified for numerous hybrid circuits from GTE production in both thin and thick film. Two circuits were chosen in particular for detailed examination since they show interesting properties. The first is the thick film circuit in Figure 7. This circuit, used in Direct Dialling Local calling number Telephony Identification, integrates 20 identical power resistors, $R=680 \Omega \pm 5 \%$, made with Dupont ink 1431 , on a $2^{\prime \prime} \times 2^{\prime \prime}$ substrate, each resistor having an area of $50 \mathrm{~mm}^{2}$. The circuit, with the 22 soldered leads, was mounted horizontally on a PCB.

Experiment were first performed powering only 2 resistors in series at $2 \mathrm{~W}$ in different positions on the substrate and then all 20 resistors connected in parallel at $8 \mathrm{~W}$. The results are recorded in Table II for ambient temperature $26^{\circ} \mathrm{C}$. From Eq. (23) the average substrate temperature from powering two resistors in series, without leads is $T_{m}=68^{\circ} \mathrm{C}$ so that when we power resistors on one edge, assuming a linear temperature gradient, the opposite edge is approximatively at $57^{\circ} \mathrm{C}$ so that the leads in reality dissipating power are not 22 but

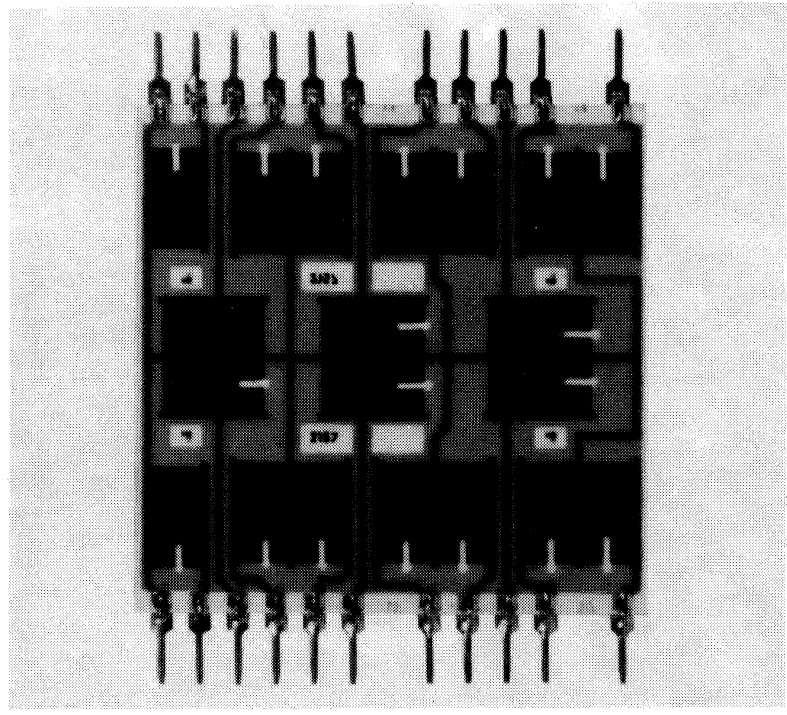

FIGURE 7 Thick film circuit.

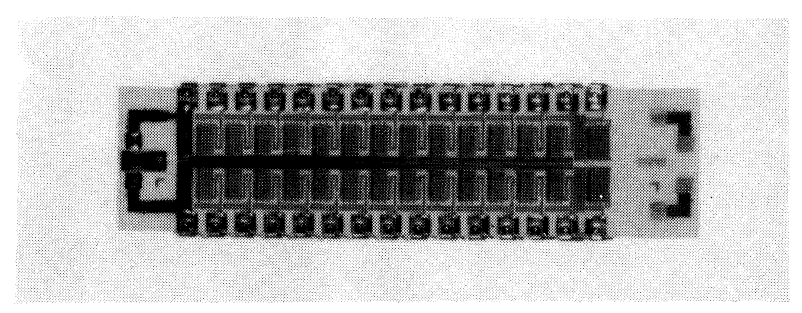

FIGURE 8 Thin film circuit.

only those to the powered resistors, and the effective temperature is closer to that calculated without the leads, also because the fact that the effective area of the resistors had been reduced by trimming was disregarded. The discrepancies in column $d$ give an idea of the care that the problem of leads requires. In effect, Eq. (12) shows that, for constant $D, P_{w} / T_{f}=H=$ constant, so that the film temperature can be written as ${ }^{4}$

$$
\begin{aligned}
& T_{f}^{\prime}=T_{a}+T_{f}=T_{a}+P_{w} / H \\
& \quad T_{a}=\text { ambient temperature }
\end{aligned}
$$

and superimposition of effects can be adopted for distributed resistors. ${ }^{5}$ However, the particular circuit had most of the resistors near the periphery of the substrate so that the high temperature on the leads is very close to the film temperature and the power dissipated by the leads is: $P_{L}=T_{f} N_{L} / R_{L}$, 
TABLE II

Experiments with thick film circuits

\begin{tabular}{|c|c|c|c|c|c|c|c|c|}
\hline & $\begin{array}{l}T \\
\left({ }^{\circ} \mathrm{C}\right)\end{array}$ & $\%$ & $\begin{array}{l}T \\
\left({ }^{\circ} \mathrm{C}\right)\end{array}$ & $\%$ & $\begin{array}{l}T \\
\left({ }^{\circ} \mathrm{C}\right)\end{array}$ & $\%$ & $\begin{array}{l}T \\
\left({ }^{\circ} \mathrm{C}\right)\end{array}$ & $\%$ \\
\hline & $a$ & & $b$ & & $c$ & & $d$ & \\
\hline $\begin{array}{l}1 \\
2 \\
3\end{array}$ & $\begin{array}{l}90 \\
84 \\
79\end{array}$ & $\begin{array}{l}+6.6 \\
+12\end{array}$ & $\begin{array}{l}80 \\
84 \\
79\end{array}$ & $\begin{array}{l}-5 \\
+1.3\end{array}$ & $\begin{array}{l}88 \\
84 \\
79\end{array}$ & $\begin{array}{l}+4.5 \\
+10\end{array}$ & $\begin{array}{c}126 \\
137 \\
132 \\
(130)\end{array}$ & $\begin{array}{l}-8.7 \\
-4.8 \\
(-3.2)\end{array}$ \\
\hline
\end{tabular}

$$
\%=\frac{\text { Actual temperature }- \text { Predicted temperature }}{\text { Actual temperature }} \times 100
$$

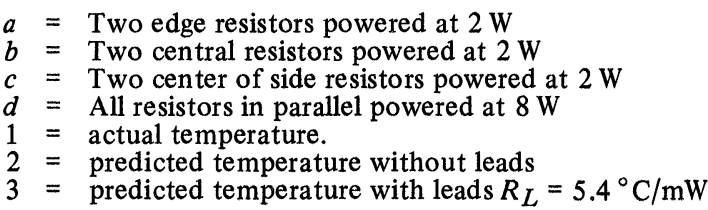

TABLE III

Experiments with thin film circuits

\begin{tabular}{|c|c|c|c|c|c|c|c|c|}
\hline$N$ & 1 & 2 & 3 & 4 & 5 & 6 & 7 & 8 \\
\hline 1 & 162 & 165 & 170 & 174 & 172 & 169 & 168 & 170 \\
\hline$\underset{\%}{2}$ & $\begin{array}{r}147 \\
+9.2\end{array}$ & $\begin{array}{l}150 \\
+9\end{array}$ & $\begin{array}{l}153 \\
+10\end{array}$ & $\begin{array}{l}156 \\
+10\end{array}$ & $\begin{array}{r}159 \\
+7.5\end{array}$ & $\begin{array}{l}162 \\
+4\end{array}$ & $\begin{array}{r}165 \\
+1.8\end{array}$ & $\begin{array}{r}169 \\
+0.6\end{array}$ \\
\hline 3 & 135 & 137 & 138 & 140 & 140 & 141 & 141 & 142 \\
\hline $\begin{array}{l}4 \\
\% \\
\end{array}$ & $\begin{array}{r}132 \\
+2.2 \\
\end{array}$ & $\begin{array}{r}134 \\
+2.2 \\
\end{array}$ & $\begin{array}{r}136 \\
+1.5 \\
\end{array}$ & $\begin{array}{ll} & 138 \\
+ & 1.4\end{array}$ & $\begin{array}{l}140 \\
+0 \\
\end{array}$ & $\begin{array}{r}142 \\
-0.7 \\
\end{array}$ & $-^{144}$ & $\begin{array}{r}146 \\
-2.8 \\
\end{array}$ \\
\hline $\begin{array}{l}N \\
1 \\
2 \\
3\end{array}$ & \multicolumn{8}{|c|}{$\begin{array}{l}\text { resistors are counted from a edge to the centre of side } \\
\text { actual temperature }\left({ }^{\circ} \mathrm{C}\right) \text { substrate vertical without leads } \\
\text { predicted temperature } \\
\text { actual temperature }\left({ }^{\circ} \mathrm{C}\right) \text { substrate horizontal with } 32 \text { leads mounted on PCB } \\
R_{L}=5.4^{\circ} \mathrm{C} / \mathrm{mW} \\
\text { predicted temperature }\end{array}$} \\
\hline
\end{tabular}

Eq. (12) can then be written

$$
\frac{P_{w}}{T_{f}}=\left(h_{f}+h\right)+2 h \sqrt{\frac{2 \pi K t D}{h A_{s}}} F+\frac{N_{L} D}{R_{L} A_{s}}
$$

to give the value in brackets in Table II.

The second circuit chosen was part of a Ladder network employed for digital to analog conversion in the GTE MP30 Pulse Code Modulation Telephon multiplex system. Thirty identical thin film resistors of Tantalum nitride were integrated on a $2^{\prime \prime} \times 1 / 2$ " alumina substrate, $R=10 \mathrm{kohm} \pm 0.05 \%$. The area of each resistor is calculated for dissipating $50 \mathrm{~mW}$ without exceeding $150^{\circ} \mathrm{C}$ at $70^{\circ} \mathrm{C}$ ambient. Experiments were performed by powering resistors at $100 \mathrm{~mW}$ each at $26^{\circ} \mathrm{C}$ ambient for easy measurements on an infrared pyrometer and the results are shown in Table III. The predicted resistor temperatures for each position were calculated from Eq. (23) and Eq. (12) assuming linear temperature gradient for the substrate from the position of the hottest resistor to that of the coolest (at each end). 


\section{CONCLUSION}

A method has been described to calculate the highest temperature for resistors on hybrid circuits and also to estimate the distribution of temperature for circuits with multiple resistors, only when component location is roughly symmetrical. The method allows calculation of the minimum area of substrate for a given power on the circuit. The effects of trimming are not considered but employing the approach of D. W. Walter ${ }^{6}$ it is also possible to compute the resulting hot spots since the temperature of the untrimmed resistor is known. The precision of the method is $\pm 5 \%$. The availability of such information on the temperature of resistors means that the stability, life and reliability of hybrid circuits can be predicted from the appropriate data extrapolated from life tests on both thin and thick film technologies.

\section{ACKNOWLEDGEMENTS}

The authors express their thanks to the staff of STAv. at GTE Telecomunicazioni for contributing experimental measurements and to Val G. H. Barker for his help in editing this paper.

\section{REFERENCES}

1. F. G. Tricomi, Lezioni di Analisi Matematica, CEDAM, Padova (1956) Ch. VII.

2. Jahnke-Emde, Tables of functions, B. G. Teubner, Leipzig and Berlin (1933) Ch. XVIII.

3. G. P. Ferraris, High capacity sputtering apparatus for hybrid microwave integrated circuits production, Thin Solid Films 24 (1974) 113-124.

4. W. H. Orr, Integrated Device and Conduction Technology, Prentice-Hall Englewood Cliffs N.J., (1971) Ch. III

5. J. R. Peck, Prediction of temperature and power handling capabilities of thin film resistors and circuits, Proc. 16 Elec. Comp. Conf. (May 1966), 68-78.

6. D. W. Walter, Computer simulation of resistors trimming, Proc. 23 Elec. Comp. Conf. (May 1973), 56-62. 

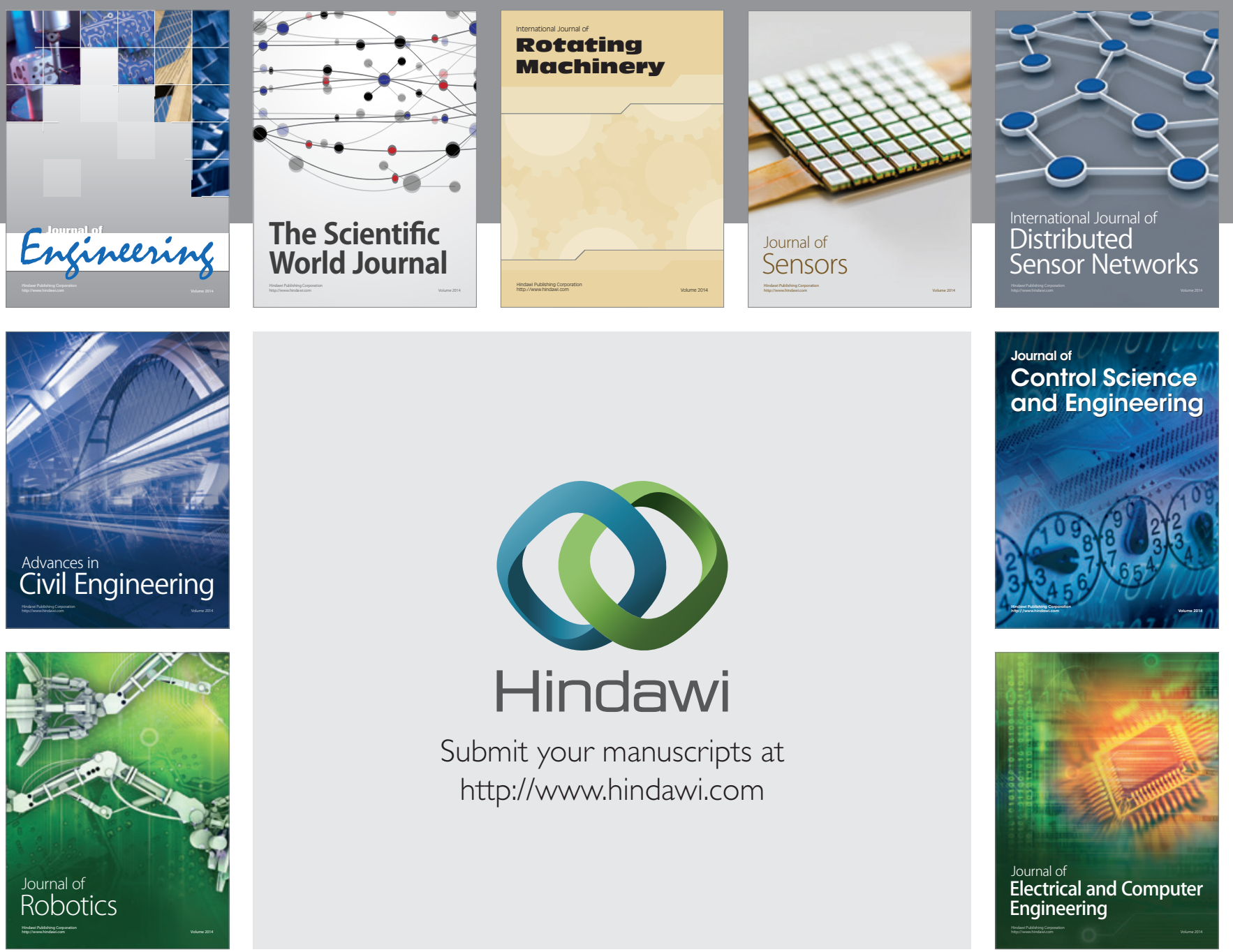

Submit your manuscripts at

http://www.hindawi.com
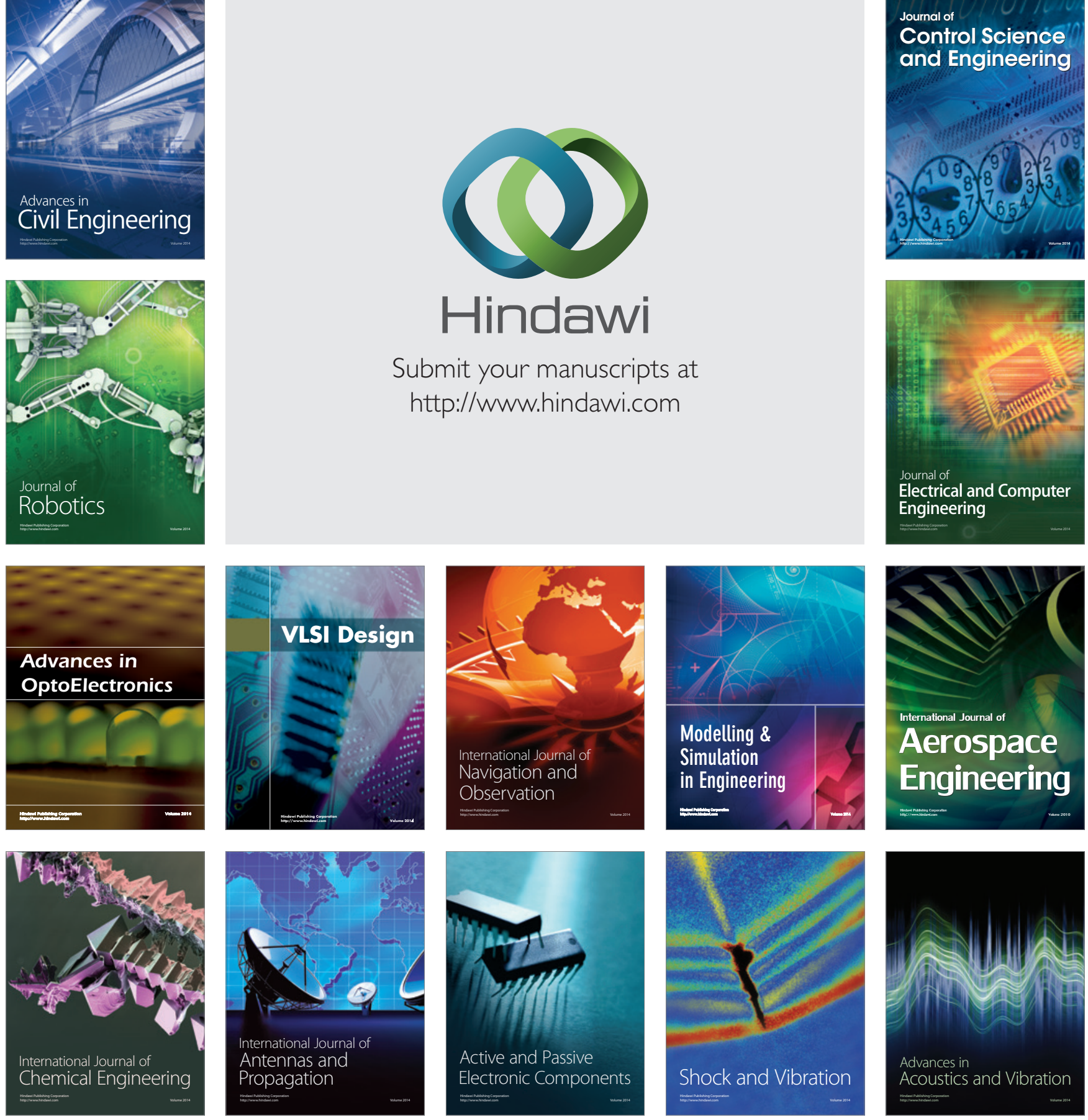